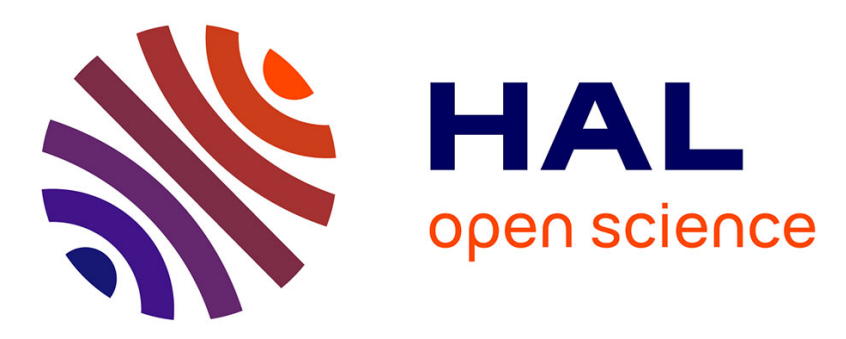

\title{
Colorblind and Multicultural Prejudice Reduction Strategies in High-Conflict Situations
}

\author{
Joshua Correll, Bernadette Park, J. Allegra Smith
}

\section{To cite this version:}

Joshua Correll, Bernadette Park, J. Allegra Smith. Colorblind and Multicultural Prejudice Reduction Strategies in High-Conflict Situations. Group Processes and Intergroup Relations, 2008, 11 (4), pp.471491. 10.1177/1368430208095401 . hal-00571700

\section{HAL Id: hal-00571700 https://hal.science/hal-00571700}

Submitted on 1 Mar 2011

HAL is a multi-disciplinary open access archive for the deposit and dissemination of scientific research documents, whether they are published or not. The documents may come from teaching and research institutions in France or abroad, or from public or private research centers.
L'archive ouverte pluridisciplinaire HAL, est destinée au dépôt et à la diffusion de documents scientifiques de niveau recherche, publiés ou non, émanant des établissements d'enseignement et de recherche français ou étrangers, des laboratoires publics ou privés. 


\title{
Colorblind and Multicultural Prejudice Reduction Strategies in High-Conflict Situations
}

\author{
Joshua Correll \\ University of Chicago \\ Bernadette Park and J. Allegra Smith \\ University of Colorado
}

\begin{abstract}
We tested colorblind and multicultural prejudice-reduction strategies under conditions of low and high interethnic conflict. Replicating previous work, both strategies reduced prejudice when conflict was low. But when conflict was high, only the colorblind strategy reduced prejudice (Studies 1 and 2). Interestingly, this colorblind response seemed to reflect suppression. When prejudice was assessed more subtly (with implicit measures), colorblind participants demonstrated bias equivalent to multicultural participants (Study 2). And, after a delay, colorblind participants showed a rebound, demonstrating greater prejudice than their multicultural counterparts (Study 3). Similar effects were obtained when ideology was measured rather than manipulated (Study 4). We suggest that conflict challenges the tenets of a colorblind ideology (predicated on the absence of group differences) but not those of a multicultural ideology (which acknowledges difference).
\end{abstract}

KEYWORDS colorblind, intergroup conflict, multicultural, prejudice

The United States Census Bureau predicts that, from 1995 to 2050, the size of the White population in the USA will increase by $7.4 \%$. During the same period, the Bureau expects the Black population to grow by about $70 \%$, American Indians by $83 \%$, Hispanics and Asians by more than $250 \%$ (Day, 1996). The states of Texas and California have already achieved 'majority minority' status: Whites now comprise less than $50 \%$ of the population. Throughout Europe and North America, societies are becoming more diverse as a function of both migration and relatively high minority birthrates (sometimes accompanied by negative population growth among Whites). These trends steadily increase the potential for intergroup contact. Like most social change, this potential creates both opportunities and risks, and social science has expended considerable energy exploring ways to maximize the former and minimize the latter. Research in this area has borne fruit, and recent decades have witnessed a dramatic evolution

\footnotetext{
Author's note

Address correspondence to Joshua Correll, Department of Psychology, University of Chicago, 5848 South University Avenue, Chicago, IL 60637, USA

[email: jcorrell@uchicago.edu]
} 
in social scientific and cultural approaches to ethnic relations (Park \& Judd, 2005).

Initial attempts within social psychology to frame intergroup contact generally strove to de-emphasize the psychological boundaries that separate groups. These strategies derive from the irrefutable, but perhaps overly simple, argument that if people do not distinguish between groups in the first place, they can never favor one group over another. In other words, prejudice cannot exist without categorization. Attempts to reduce or eliminate prejudice therefore focused on de-emphasizing categories by redefining subordinate groups in terms of a common ingroup identity (e.g. in the USA, Whites, Blacks, Hispanics, Asian Americans, American Indians, etc., can all be recategorized as American; Gaertner, Dovidio, Nier, Ward, \& Banker, 1999; Gaertner, Mann, Murrell, \& Dovidio, 1989), or, alternatively, on reducing the salience of group membership and focusing instead on personal identity (Brewer, 1991; Brewer \& Miller, 1984). These approaches stress a colorblind $(\mathrm{CB})$ ideology in that they minimize attention to racial and ethnic divisions. Demonstrations in both laboratory and field show that these CB approaches can significantly reduce the expression of prejudice (Gaertner et al., 1999).

In spite of the ideological purity of the CB perspective, recent work has begun to argue that group differences can and should be acknowledged. This change reflects, perhaps, a growing awareness of some of the more subtle realities of a multi-ethnic society. First, human beings seem to automatically inexorably divide their social world according to categories like gender, age and race (Brewer, 1988). Even when it is irrelevant to the task at hand for example, neuropsychological research suggests that perceivers differentiate racial groups within a fraction of a second (Ito \& Urland, 2003). People simply may not be able to ignore group membership completely. Second, individuals may not want to give up their ethnic or racial affiliations. A CB world, despite certain sociological advantages, threatens to strip the individual of part of his or her identity. It may seem counterproductive for minority groups to tenaciously maintain their collective identities. After all, minorities are often disadvantaged
(Sidanius \& Pratto, 1999) and arguably have the most to gain from the widespread adoption of a CB ideology. But pitted against these advantages, the smaller, more cohesive minority group may confer distinct psychological benefits to its members (Brewer, 1991; Correll \& Park, 2005; Crocker \& Major, 1989; Pickett \& Brewer, 2001; Wolsko, Park, \& Judd, 2006). Third, explicitly acknowledging the divisions between groups may, in some cases, harmonize intergroup relations. Category differentiation can clarify roles and, in so doing, minimize the perception that groups are in direct competition with each other (Brown \& Wade, 1987; Hornsey \& Hogg, 2000).

In light of the apparent inevitability of social categorization as well as its potential benefits, several recent perspectives on intergroup relations have advocated a framework that both acknowledges and appreciates differences between groups. Various incarnations of this idea include mutual intergroup differentiation (Hewstone \& Brown, 1986), the multimodal perspective (Mummendey \& Wenzel, 1999), a revised version of the common ingroup identity model (Gaertner et al., 2000), and the multicultural (MC) ideology (Wolsko, Park, Judd, \& Wittenbrink, 2000; Wolsko et al., 2006). Recent data suggest that social categorization need not promote prejudice (Deffenbacher, Park, Judd, \& Correll, 2007) and that participants who acknowledge and appreciate diversity may express lower levels of prejudice (on par with those who adopt a CB perspective; Wolsko et al., 2000). For the sake of simplicity, in the remainder of this article, we use the term $M C$ to refer generally to strategies that stress the appreciation of group differences.

We have focused thus far on the concept of prejudice or intergroup bias. These terms describe the tendency to evaluate ingroups (groups to which an individual belongs) more favorably than outgroups (groups to which the individual does not belong). In other words, prejudice represents an attitude-a subjective phenomenon. Of course, these subjective evaluations often interact with more objective characteristics of the situation. Research has long suggested that intergroup bias depends on the functional relationship between the groups. When groups compete with one another for 
scarce resources, for example, prejudice tends to increase (Levine \& Campbell, 1972; Sherif, Harvey, White, Hood, \& Sherif, 1961). That is, the introduction of (objective) intergroup conflict tends to exacerbate (subjective) feelings of bias. Realistic group conflict theory, a groundbreaking perspective on prejudice, formally proposed this relationship, and it remains a foundation for much of the theory and research on intergroup relations (Brewer \& Brown, 1998; Esses, Jackson, \& Armstrong, 1998; Hewstone, Rubin, \& Willis, 2002; Sidanius \& Pratto, 1999; for a review see Correll \& Park, 2005).

In spite of the connection between conflict and bias, we are aware of no research that has experimentally examined the impact of conflict on $\mathrm{CB}$ and MC prejudice-reduction strategies. It is admirable to address the issue of prejudice under any circumstances, but for at least two reasons it seems crucial to consider how these strategies fare under conditions of intergroup stress. First, although prejudice often exists in relatively harmonious intergroup contexts, intergroup conflict may be expected to exacerbate bias (Sherif et al., 1961). Bias should be more pronounced-and bias reduction should therefore be more critical and more difficult to achieve-during periods of intergroup conflict. Second, the fact that a prejudice-reduction strategy works in the absence of conflict does not necessarily mean that it will work when tension is high. As discussed in the following sections, the efficacy of CB and MC approaches may change dramatically as a function of intergroup conflict.

\section{Multiculturalism in high-conflict situations}

As suggested by realistic group conflict theory, the introduction of conflict between groups should generally increase the magnitude of prejudice. But participants who espouse an MC ideology may be especially vulnerable to intergroup tension because, by definition, $\mathrm{MC}$ strategies promote the clear demarcation of groups. In conflict situations, the salience of these divisions may induce partisans to attribute their disagreement to the nature or essence of the outgroup (e.g. 'That's just the kind of people they are.'). This argument draws on the category divide hypothesis, which suggests that group boundaries often serve as an explanation for perceived group differences, including differences that arise from conflicts of interest (Miller \& Prentice, 1999). If conflict appears to be rooted in the unchangeable essence of the outgroup, individuals on both sides of the issue may abandon efforts at reconciliation and prepare for a fight. This line of reasoning suggests that MC participants may respond to conflict with even greater hostility than individuals who adopt no prejudice-reduction strategy at all.

A more hopeful alternative is that individuals who adopt a MC ideology will exhibit reduced levels of prejudice in spite of the conflict. Multiculturalism, after all, recognizes that groups should and do differ, and that differences should be tolerated, accepted, and even appreciated. From this vantage point, an intergroup dispute may be cast simply as a kind of difference, andin the mind of the observer-reactions to this unpleasant difference may be tempered by the awareness of other, more enjoyable differences (e.g. the groups' distinct contributions to a rich common culture). Although this benefit of the MC perspective would almost certainly break down in the case of extreme intergroup conflict (e.g. violence), the strategy may ameliorate bias in more moderate situations.

\section{Colorblindness in high-conflict situations}

CB ideologies present a different set of strengths and liabilities. Donald Campbell (1967), who pioneered theoretical and empirical efforts to address intergroup bias, recognized from the beginning that $\mathrm{CB}$ strategies, predicated on the absence of group differences, may falter when individuals are forced to acknowledge that groups really do vary. As he writes,

Remedial efforts focused on denying group differences are apt to be unwittingly endorsing the most mischievous ... misperceptions-wrongly agreeing that the particular group differences cause the hostility, unwittingly agreeing that were the actual group differences to exist, discrimination would be justified. (p. 827) 
The very existence of intergroup conflict, then, may undermine the premise of colorblindness. How will CB participants cope with the logical inconsistency between an ideology, which denies difference, and an intergroup conflict, which exemplifies it? If group members admit that their interests conflict with those of the outgroup, the prejudice-reducing benefits of the CB ideology may disintegrate along with its founding assumption. If so, $\mathrm{CB}$ participants should respond to conflict with as much hostility as anybody else.

But again, there is an alternative, more optimistic possibility. Participants may adhere so strictly to the tenets of the CB ideology that they will trivialize or even deny the conflict. If they can effectively ignore the disagreement, CB participants may preserve the illusion of intergroup uniformity and protect the integrity of their ideology. This is an intriguing possibility. It depends on the individual's capacity to suppress the cognitive and affective implications of conflict and steadfastly maintain that the two groups are, in truth, no different from one another. This process (like the MC process involving tolerance of conflict-as-difference) might be expected to collapse in cases of extreme conflict, but, as a short-term strategy during moderate-level conflict, the tendency to ignore disagreement and reassert the colorblind ideology may effectively preserve at least the veneer of goodwill.

\section{The current research}

The studies that follow tested CB and MC approaches under conditions of both low and high levels of intergroup conflict. In the absence of conflict, we expected both CB and MCideologies to reduce bias relative to a control condition. Such a demonstration would simply replicate previous research (Gaertner et al., 1999; Wolsko et al., 2000). We were chiefly concerned with the performance of the two strategies in conflict situations. As outlined earlier, there is some basis for concern. Both $\mathrm{CB}$ and MC strategies may fail as conflict grows more severe. This seems to present a particular liability for multiculturalism which may actually backfire and induce greater prejudice. However, it is also possible that $\mathrm{CB}$ and MC strategies will retain some utility during conflict-though through very different mechanisms. Colorblindness may prompt participants to deny the existence of a dispute, or deny the role of group membership in the dispute (e.g. disagreements about affirmative action might be attributed to economic, not ethnic, differences). Multiculturalism may allow participants to recognize and accommodate the dispute as one (unpleasant) difference among a number of more palatable intergroup distinctions.

\section{Study 1}

\section{Method}

Participants One hundred and seventeen White students ( $61 \%$ female) in an introductory psychology course at the University of Colorado (CU) took part in this study, in partial completion of a course requirement. ${ }^{1}$

Design We randomly assigned participants to a control condition or to one of two ideological conditions in which participants received a persuasive message stressing the importance of adopting either a CB or an MC perspective on interethnic relations. Crossed with this manipulation of Ideology, we assigned participants to one of two levels of Conflict, low versus high. The design of the study, then, was a 3 (Ideology: control vs. CB vs. MC) $\times 2$ (Conflict: low vs. high) between-subjects design.

\section{Materials and procedure}

Ideology manipulation The manipulation of ideology was taken directly from Wolsko et al. (2000; see also Richeson \& Nussbaum, 2004). Participants in both the $\mathrm{CB}$ and MC conditions were asked to read a paragraph describing the testimony of sociologists and political scientists who stressed the importance of either ignoring ethnic divisions and learning to see others simply as fellow human beings (CB), or appreciating ethnic diversity and learning to see variation as an asset to society (MC). To strengthen the effect of these manipulations, participants in both ideological conditions were asked to list several benefits of the perspective about which 
they had read and, finally, to examine a list of benefits ostensibly proposed by other students and place a check mark next to any items they had considered. Control participants spent a comparable time thinking about ethnic relations in the USA and listing their thoughts. Upon completion of their tasks, all participants were asked to complete a manipulation check, rating the degree to which they perceived ethnic groups as distinct and meaningful $(1$, not at all to 9 , extremely).

Conflict manipulation (newspaper article) Participants then read a fake newspaper article describing a proposal to alter the system through which students register for classes at CU. The new policy was ostensibly being considered by the school's administration. We chose to focus on course registration because pilot testing indicated that students often found it difficult to enroll in classes they wanted or needed. We reasoned that competition for classes (a scarce resource) would provoke fairly strong reactions, capturing the essence of intergroup conflict in the real world. Both the high- and low-Conflict articles described a policy advanced by the Hispanic Student Association (a fictional organization), which would give preferential treatment to minority students in the process of registering for classes. The policy was presented as an effort to make minority students feel more welcome at CU (the student body is roughly $90 \%$ White). The articles were identical except for a few key passages. The lowConflict article described a proposal that would expand popular classes, allowing minorities who would have otherwise been waitlisted to enroll. Critically, this proposal would not reduce the space available to White students. Class size would simply be increased to accommodate the minority students-a slight adjustment given the small percentage of minorities at CU. The high-Conflict article described an 'early registration' period during which minority (but not White) students would be able to enroll in popular classes, taking valuable spaces and further limiting the availability of those classes for Whites (a zero-sum situation). Both articles suggested that the administration was seriously considering the policy change.

Participants were told that the psychology department had been contacted by the administration and asked to help assess student reactions to the proposal. According to this cover story, student comments about the policy would be delivered to the committee making the ultimate decision. As part of this 'feedback,' participants completed a manipulation check, rating the degree to which the proposed policy would increase or decrease minority and, separately, White students' chances of successfully registering for classes (1, decrease; 5 , no effect; 9 , increase).

Measures of intergroup bias Finally, participants were given a packet of questionnaires to assess intergroup bias. Participants were told that these measures had been included by the psychology researchers and would not be shared with the administration. This packet included a group warmth thermometer, on which participants rated how warmly (100) or coolly (0) they felt toward a number of groups, including Whites and Hispanics as well as Blacks, Native Americans, and Asian Americans. Subsequently, participants completed eight Peabody sets (Peabody, 1967). A Peabody set consists of two semantic differential scales, which assess the same conceptual dimension, but which vary in their evaluative connotations. For example, items anchored with passive-assertive and pushy-cooperative both involve surgency. In the case of pushy-cooperative, surgency is presented as undesirable, whereas in the case of passive-assertive, surgency is presented as desirable. Participants first rated Hispanics on these items, and then Whites, in each case marking a 6 -inch line with an $\mathrm{X}$ to indicate the point between the two adjectives that best characterized the group. Additional sets included lax-rigorous/lenient-strict, reckless-cautious/ daring-fearful, selective-undiscriminating/ picky-broadminded, conceited-modest/selfconfident-insecure, sociable-reclusive/ chatty-reserved, unreflective-intelligent/commonsensical-bookish, and insolent-respectful/ free-spirited-conventional. 
Finally, participants were extensively debriefed. During this discussion, we attempted to ascertain whether participants believed the story about the new registration policy. We then explained that the policy was not actually being considered by the administration and outlined the purpose and importance of the manipulation, taking care to answer all questions and allay any concerns.

\section{Results and discussion}

In the present studies, we examined condition differences using a 3 (Ideology: Control vs. CB vs. MC) $\times 2$ (Conflict: high vs. low) analysis of variance (ANOVA). With regard to the effects of Ideology, we specified two orthogonal questions, each of which depends on a single-degree-offreedom test. First, we wished to know whether $\mathrm{CB}$ and MC differed from one another. Second, we wished to know whether the two experimental conditions (CB and $\mathrm{MC}$ ), on average, differed from the control condition.

Manipulation checks To check the efficacy of our Ideology manipulation, we examined participants' ratings of distinctiveness. ${ }^{2}$ As expected, participants in the $\mathrm{CB}$ condition $(M=4.90)$ rated ethnic groups as less distinct than participants in the MC condition $(M=6.18), F(1,103)=9.86$, $p=.002$. The control condition fell between the two experimental conditions $(M=5.92)$ and did not differ from their average, $F(1,103)=1.19$, $p=.28$. No other effects were significant.

To assess the effect of our Conflict manipulation, we examined perceptions of the degree to which the registration policy would (i) help or hurt minorities, and (ii) help or hurt Whites. Not surprisingly, participants in all conditions felt that the policy would help minorities ( $M=8.33$ on a 9 -point scale), and Conflict did not affect ratings of minority benefit (high Conflict $M=8.41$, low Conflict $M=8.25), F(1$, $111)=1.04, p=.31$. That is, the policy was seen as uniformly favorable to minorities, whether or not it threatened White interests. Interestingly, MC participants $(M=8.50)$ saw the policy as marginally more beneficial to minorities than did CB participants $(M=8.13)$, $F(1,111)=3.13, p=.080$. Again, the control condition fell in between the two ideological conditions $(M=8.36)$ and did not differ from their average, $F(1,111)=.05, p=.82$.

More importantly, ratings of the policy's cost to Whites showed a pronounced effect of Conflict, $F(1,111)=57.61, p<.0001$. As intended, participants in the high-Conflict condition $(M=2.38)$ saw the policy as less favorable to White students than did participants in the low-Conflict condition $(M=4.00)$. Open-ended responses also suggested that the high-Conflict condition aroused frustration and even a degree of anger. One participant wrote (in large print), 'Not cool CU!!!' Our analysis of the rating data also revealed an unexpected marginal interaction between Conflict and the control versus ideology contrast code, $F(1,111)=3.61, p=.060$. This result reflects the control condition's tendency to rate the policy as less favorable to Whites (relative to MC and $\mathrm{CB}$ ) when conflict was low, but as more favorable when conflict was high.

These findings suggest that we effectively manipulated both Ideology and Conflict, inducing $\mathrm{CB}$ participants to conceive of ethnic groups as less distinct (and MC participants to conceive of them as more distinct), and inducing high-Conflict participants to perceive the policy as more costly to their interests than low-Conflict participants (though both conditions recognized the potential benefit for minorities).

Intergroup bias We computed two indices of bias, one based on the group warmth thermometer, and one based on the Peabody sets. For the warmth ratings, we computed a simple difference score representing the degree to which each participant felt more warmly toward Whites than toward Hispanics (whose fictional student organization was promoting the policy change). For the Peabody sets, we calculated the degree to which participants ascribed positive (vs. negative) traits to each group. Like the thermometer, we defined prejudice as greater positivity toward Whites than Hispanics. A pattern of prejudice might be indicated by rating Whites as more assertive than Hispanics on the assertive-passivescale and more cooperative than Hispanics on the pushy-cooperativescale. Peabody sets are noteworthy because such a response 
would require participants to rate Whites as both high and low on surgency (high when surgency is desirable, low when it is undesirable). Accordingly, this measure of prejudice is largely unconfounded with the particular semantic content of the traits involved. That is, high scores on the prejudice measure cannot result simply from differences in the perceived prevalence of particular characteristics among one group versus another. The thermometer and Peabody measures were correlated, $r(117)=.47, p<.001$. To improve reliability, we standardized and averaged the two scores to form an overall bias index.

Analysis of intergroup bias revealed several effects. The high-Conflict condition differed from the low-Conflict condition, $F(1,111)=5.04$, $p=.027$, and the $\mathrm{CB}$ condition differed from the MC condition, $F(1,111)=4.63, p=.034$. These main effects were qualified by an interaction between Conflict and the control versus ideology contrast code, $F(1,111)=4.62, p=.034$, as well as a marginal omnibus Conflict $\times$ Ideology interaction, $F(2,111)=2.89, p=.060$. (See Table 1 for condition means.)

To clarify these effects, we examined the impact of Ideology separately at high and low levels of Conflict. When Conflict was low, the CB and MC conditions did not differ from one other, $F(1,111)=0.53, p=.47$. But, on average, participants in both ideological conditions tended to report less bias than those in the control condition, $F(1,111)=2.79, p=.098$. These effects largely replicate previously documented effects of the MC and CB manipulations (Wolsko et al., 2000). When conflict was high, however, we obtained a very different pattern. The CB condition reported significantly less bias than the MC condition, $F(1,111)=5.52, p=.021$, and the control condition did not differ from the CB-MC average, $F(1,111)=1.90, p=.17$. On the surface, this result seems to suggest that $\mathrm{CB}$ strategies of prejudice reduction outperform MC strategies during conflict.

Our suspicions were aroused, however, when we examined the main effect of Conflict. In line with prior research (Sherif et al., 1961), we expected that bias would increase in a highconflict situation. In the present study, participants in the $\mathrm{CB}$ and control conditions counterintuitively reported less bias in the high-Conflict condition than in the low-Conflict condition (for those two conditions, $F(1,111)=$ $4.80, p=.030)$. Indeed, only the MC condition showed the pattern predicted by realistic group conflict theory, in which higher levels of conflict produced greater bias (although the means did not differ statistically). We suspected that the CB participants (and perhaps the controls) were attempting to conceal any resentment aroused by the conflict. Recall that the CB manipulation stresses the importance of ignoring group differences. A conflict of interest highlights distinctions between groups, so recognition of these differences violates the fundamental assumption of the CB ideology. Participants in that condition may therefore have been motivated to conceal, or even suppress, their concerns about the outgroup. (It also seems reasonable to suggest that a similar process was operating among the control participants. However, in the absence of a specific ideological manipulation, we lack concrete expectations about the processes at work in that condition.) By contrast,

Table 1. Means $(S D)$ of standardized index of intergroup bias as a function of Ideology (control, colorblind or multicultural) and Conflict (low or high) from Study 1

\begin{tabular}{lcrr}
\hline & \multicolumn{3}{c}{ Ideology } \\
\cline { 2 - 4 } Conflict & Control & CB & MC \\
\hline Low & $0.37(1.09)$ & $-0.07(0.54)$ & $0.12(0.62)$ \\
High & $-0.37(0.60)$ & $-0.36(0.64)$ & $0.21(0.87)$ \\
\hline
\end{tabular}

Note: Intergroup bias is based on a warmth thermometer rating of Whites minus Hispanics, and ratings on Peabody sets of the degree to which positive traits were ascribed to Whites, more so than to Hispanics. Each measure was first standardized and then averaged to form the composite measure. 
MC participants, who have been told that group differences are acceptable, may see the disagreement as less problematic for intergroup relations in the long run. MC individuals may therefore be more willing to express resentment in a high-conflict situation.

Study 1 relied entirely on questionnaire measures, which are subject to strategic responding. This limitation presents a challenge in situations where publicly expressed views and privately held views may diverge. Study 2 sought to examine prejudice more subtly by including an implicit measure of intergroup attitudes. Implicit measures of prejudice have gained prominence in social psychology because, in theory, they can assess attitudes that participants would rather conceal (Devine, 1989; Greenwald, McGhee, \& Schwartz, 1998). That is, the desire to appear unbiased does not necessarily translate to unbiased performance on these indices. If conflict sparks resentment, which CB participants feel but do not want to admit, they should report relatively egalitarian attitudes on explicit measures. But these individuals may have greater difficulty inhibiting prejudice on implicit measures. In Study 2, we therefore predicted that, for CB participants, explicit and implicit bias measures should diverge. As in Study 1, bias should be low on explicit measures (over which participants have conscious control), but their resentment should manifest itself on more difficult-to-control implicit measures (Fazio, Jackson, Dunton, \& Williams, 1995), reaching levels equivalent to the $\mathrm{MC}$ and control conditions.

\section{Study 2}

\section{Method}

Participants and design One hundred and fourteen White students in an introductory psychology course ( $70 \%$ female) took part in this study in partial satisfaction of a course requirement. ${ }^{3}$ Like Study 1 , the between-subjects portion of this experiment followed a 3 (Ideology: control vs. CB vs. MC) $\times 2$ (Conflict: high vs. low) design. However, in Study 2, we also included a within-subjects factor, Type of Measure, with two levels, Explicit and Implicit.
Materials and procedure Manipulation of both Ideology and Conflict was accomplished as in Study 1. However, we included a more comprehensive manipulation check after the Ideology manipulation, consisting of an eight-item group differentiation scale (Wolsko et al., 2006), including items such as 'A Black person is really just another White person but with dark skin.'

Measures of explicit bias We developed a computerized questionnaire, which assessed percent estimates for a number of groups, including Whites and Hispanics. This measure asked participants to rate the prevalence of eight characteristics for both Whites and Hispanics. Ratings were made on scales ranging from 1 $(0-10 \%)$ to $10(91-100 \%)$, with $10 \%$ intervals in between. Traits included intelligent, patriotic, self-centered, and uptight (stereotypic of Whites), strong emotional bonds to family, religious, sexist and violent (stereotypic of Hispanics). Half of the traits in each group were positive in valence, and half were negative. In Studies 2 and 3, we used percent estimates rather than Peabody sets because they are simpler to implement, but it is important to note that, because valence and stereotypicality vary orthogonally in the percent estimate traits, they (like the Peabody sets) minimize the confound between prejudice and stereotyping. The questionnaire was presented as a pilot test for a project being conducted by another researcher. The measures were presented on a series of screens, with one screen for each group.

Measure of implicit bias To assess implicit intergroup bias, we adapted the Extrinsic Affective Simon Task (EAST; De Houwer, 2003). The EAST is similar to the Implicit Associations Test (Greenwald et al., 1998) in that it forces participants to classify two sets of stimuli-in this case, names and words-using a single set of response options. Bias is assessed as the extent to which one task interferes with the other. In the current study, the first classification involved differentiating 20 White and 20 Hispanic surnames (e.g. Roberts, Johnson, Ramirez, Gonzalez) according to their ethnicity, pressing a blue button for Whites and a green button 
for Hispanics. The names appeared in white print on a black background. On separate trials, intermingled with the name-categorization task, participants were asked to categorize other words according to color. These words appeared in a blue-green typeface. Half of the words were primarily blue and half were primarily green, but the two hues were chosen to be difficult to discriminate. In addition, 20 of the words were positive in valence (e.g. rainbow, happy) and 20 were negative (e.g. cockroach, vomit). Because participants typically (if inadvertently) read words when they attempt to categorize them by color (Stroop, 1935), those who implicitly favor Whites over Hispanics should be faster to categorize positive words when those words appear in blue (requiring the button associated with Whites) rather than green (requiring the button associated with Hispanics). At the same time, they should be faster to categorize negative words when those words appear in green rather than blue. The EAST consisted of four blocks. The first two blocks (20 trials each) provided opportunities to practice the nameand color-categorization tasks, respectively. The third block, consisting of 40 trials, allowed participants to practice the two tasks together. The final block constituted the test trials, presenting each color-word once in blue and once in green, and presenting each name twice, for a total of 160 trials.

\section{Results and discussion}

Manipulation checks Our three manipulation checks revealed patterns similar to Study 1. CB participants $(M=4.13)$ endorsed lower levels of distinctiveness among ethnic groups than did MC participants $(M=5.83), F(1,108)=12.80$, $p=.001$. Control participants $(M=4.90)$ fell in between the two ideologies and did not differ from their average, $F(1,108)=0.05$, $p=.83$. Participants generally rated the policy as helpful to minorities $(M=8.19)$, and, in line with expectations, this rating did not depend on condition. Further, as predicted, participants in the high-Conflict condition $(M=2.34)$ rated the policy as more harmful to Whites than participants in the low-Conflict condition
$(M=3.94), F(1,107)=34.33, p<.0001$. No other effects were significant.

\section{Data preparation}

Percent estimates We calculated the degree to which participants ascribed positive and negative attributes to Whites and, separately, Hispanics. We then calculated bias as the degree to which participants ascribed positive attributes to Whites more readily than negative attributes, but ascribed negative attributes to Hispanics more readily than positive attributes. [Explicit Bias $=($ White-positive - White-negative $)-$ (Hispanic-positive-Hispanic-negative)]

Extrinsic affective Simon task We calculated implicit bias in the EAST as specified by De Houwer (2003). The analysis focused on correct responses to trials involving the blue-green words, which were positive or negative in valence. Reaction times from these trials falling below $300 \mathrm{~ms}$ or above $3000 \mathrm{~ms}$ were recoded to these minimum and maximum values, respectively. All latencies were then $\log$ transformed, and the resulting values were averaged within word valence and response button, yielding four means: positive words associated with Whites, negative words associated with Whites, positive words associated with Hispanics, negative words associated with Hispanics. From these four means, we calculated a measure of implicit bias analogous to our measure of explicit bias: the degree to which White names facilitate positive words more than negative words, whereas Hispanic names facilitate negative words more than positive words. [Implicit Bias $=$ (White-negative-Whitepositive $)$ - (Hispanic-negative-Hispanicpositive)]

Explicit intergroup bias On average and controlling for condition, the explicit bias index revealed negative intergroup bias (i.e. an evaluative preference for the outgroup), $F(1,108)=42.64, p<.001$. We repeatedly obtain this pattern with the percent estimate measure. However, the present research is concerned primarily with the effect of our manipulations on the magnitude of bias, not with the average 
level of bias, itself. Between-subjects analysis revealed that, across levels of Conflict, the control versus ideology contrast was marginally significant, $F(1,108)=2.62, p=.11$, reflecting lower bias in the $\mathrm{CB}$ and MC conditions than in the control condition (see Table 2 for means). Importantly, and in line with our expectations, the contrast pitting $\mathrm{CB}$ against $\mathrm{MC}$ interacted with Conflict, $F(1,108)=4.04, p=.047$. The data replicate the pattern found in Study 1: when Conflict was low, $\mathrm{CB}$ and MC did not differ from one another, $F(1,108)=0.94, p=.33$; but when Conflict was high, the $\mathrm{CB}$ condition tended to express less bias than the MC condition, $F(1,108)=3.46, p=.066$.

Implicit intergroup bias Controlling for condition, the EAST index revealed a non-significant pattern of pro-White bias, $F(1,108)=2.16$, $p=.15$. Perhaps because the EAST relies on relatively subtle Stroop-like processing of the meaning of the color words (rather than explicit valence categorizations, as does the IAT), we typically obtain relatively small main effects with this task. However, as with the explicit measure, our primary interest is not in the overall level of pro-White bias, but rather in the variability of that bias as a function of condition. Importantly, analysis of the EAST index revealed an interaction between Conflict and the control versus ideology contrast, $F(1,108)=3.96, p=.050$ (see Table 2 for means). When Conflict was low, the pattern of implicit bias was similar to that of explicit bias. The $\mathrm{CB}$ and MC conditions, on average, showed marginally lower bias than the control condition, $F(1,108)=3.28, p=.073$, but $\mathrm{CB}$ and MC did not differ from each other, $F(1,108)=0.32, p=.57$. (This result is rather striking in its own right. It suggests that, in the absence of conflict, the induction of $\mathrm{CB}$ and MC ideologies may promote more positive attitudes toward an outgroup, even on an implicit measure, but see Richeson \& Nussbaum, 2004.) Before turning to the high-conflict condition, it is important to recall that, when conflict was high, CB participants reported less explicit bias than their MC counterparts. We have suggested that this decrease may not be due to more positive feelings, but rather that it constitutes an attempt on the part of the CB participants to downplay any resentment they feel (in line with the tenets of a CB ideology). In other words, $\mathrm{CB}$ participants may actually be just as upset by the conflict as MC participants. In line with this possibility, an analysis of implicit bias in the high-Conflict condition showed no effect of ideology, whatsoever. Neither the control versus ideology nor the CB versus MC contrast was significant, $F$ values $<1, p$ values $>.34$. (See Table 2 for means.)

\section{Relationship between implicit and explicit} bias The foregoing analyses demonstrate a sort of dissociation between explicit and implicit

Table 2. Means $(S D)$ of explicit intergroup bias and implicit intergroup bias as a function of Ideology (control, colorblind or multicultural) and Conflict (low or high) from Study 2

\begin{tabular}{|c|c|c|c|c|}
\hline & & \multicolumn{3}{|c|}{ Ideology } \\
\hline & & Control & $\mathrm{CB}$ & MC \\
\hline Bias measure & Conflict & & & \\
\hline \multirow[t]{2}{*}{ Explicit } & Low & $-0.84 \quad(2.07)$ & $-1.20 \quad(1.55)$ & $-1.80 \quad(1.82)$ \\
\hline & High & -0.71 & $-1.96 \quad(1.96)$ & $-0.79 \quad(2.21)$ \\
\hline \multirow[t]{2}{*}{ Implicit (log-ms) } & Low & $0.056(0.151)$ & $-0.010(0.102)$ & $-0.035(0.138)$ \\
\hline & High & $0.011(0.146)$ & $0.070(0.129)$ & $0.026(0.177)$ \\
\hline
\end{tabular}

Note: Explicit bias is based on percentage estimates of the prevalence of positive minus negative traits for Whites relative to Hispanics. Implicit bias reflects reaction times in the EAST, calculated as the degree to which responses to negative words were slower when they shared the same response as White (vs. Hispanic) plus the degree to which responses to positive words were slower when they shared the same response as Hispanic (vs. White). For both measures, higher numbers indicate greater bias. 
measures in the $\mathrm{CB}$ condition. We suspect that $\mathrm{CB}$ participants, who have been told that group differences are problematic, may experience antipathy or resentment on an implicit level but refuse to explicitly acknowledge that negative reaction because doing so would violate the principles of the CB ideology. Accordingly, implicit and explicit biases diverge. It is critical to note that this inverse relationship should hold regardless of the source of resentment. In the present studies, we manipulate conflict over course enrollment, but the same inverse relationship should hold even if the prejudice stems from idiosyncratic, personal reasons. For example, a participant in the low-Conflict CB condition may experience a similar implicitexplicit dissociation if he or she (personally) resents Hispanics due to concerns over illegal immigration. MC participants, by contrast, have been told that differences and disagreements are acceptable. They may therefore be more willing to express subjective discontent on explicit measures. For the MC participants, then, implicit and explicit bias should correspond. If this explanation is correct, we might expect a more positive correlation between implicit and explicit measures for the MC condition than for the $\mathrm{CB}$ condition.
Beginning with our basic $3 \times 2$ ANOVA, and taking explicit bias as the criterion, we added implicit bias as a predictor to assess the relationship between it and explicit bias. We then expanded this model to test whether implicit bias interacts with the Ideology manipulation to predict explicit bias. ${ }^{4}$ This analytic approach is desirable because it not only assesses the differential relationship between implicit and explicit bias as a function of Ideology, but it simultaneously controls for main effects (on both indices) of the Conflict manipulation. This analysis revealed that the relationship between implicit and explicit bias did indeed depend on the CB versus MC contrast, $F(1$, $105)=5.34, p=.023$. As shown in Figure 1, the partial relationship between implicit and explicit bias (i.e. the slope of the line) was more positive in the $\mathrm{MC}$ condition than in the $\mathrm{CB}$ condition, and indeed approached a significantly negative relation among the $\mathrm{CB}$ participants, $F(1,105)=3.17, p=.078$.

Again, it is important to note that, theoretically, the $\mathrm{CB}$ dissociation between implicit and explicit measures should not be induced by our Conflict manipulation. The same pressure to minimize or ignore group differences should hold for $\mathrm{CB}$ participants in both the low- and high-Conflict

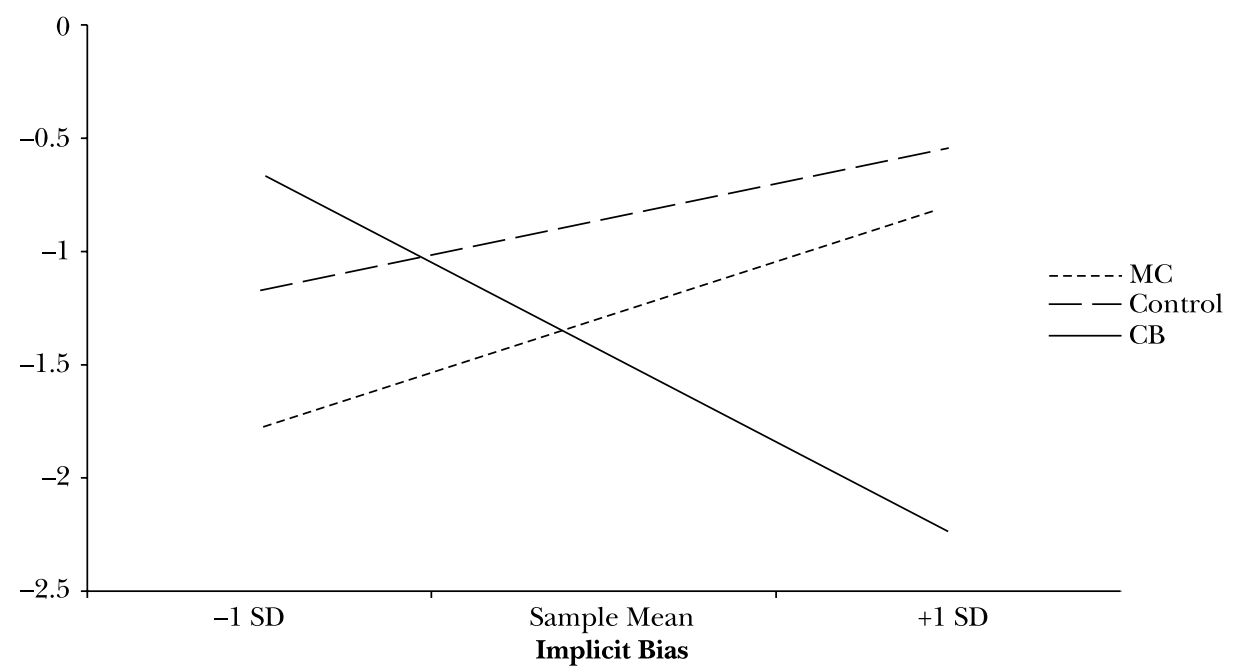

Figure 1. The relationship between explicit and implicit measures of intergroup bias as a function of Ideology (control, colorblind, or multicultural). 
conditions. Indeed, a test of the 3-way interaction between implicit bias, Conflict and the $\mathrm{CB}$ versus MC contrast was not significant, $F(1,102)=0.48$, $p=.49$. This analysis suggests that the nature of the implicit-explicit relationship does not differ between the two Conflict conditions. Rather, in the high-Conflict condition, we simply make salient a particular source of intergroup tension. In so doing, we increase the level of implicit bias and correspondingly decrease the level of explicit bias that CB participants are willing to report.

In the $\mathrm{CB}$ condition, greater implicit bias was associated with lower explicit prejudice, suggesting that participants compensated for their internal resentment with overly positive evaluations of the outgroup. In as much as CB participants were told that any group difference is problematic, this type of suppression may reflect an experimentally induced motivation to present an egalitarian façade (Fazio et al., 1995; Plant \& Devine, 1998). Such a motivation may certainly be desirable if it reduces the overt expression of bias, but research has also shown that suppressing bias can have unintended and ironic consequences. Suppression can actually increase bias when participants finally relax their guard (Wegner, Schneider, Carter, \& White, 1987). For example, Macrae and his colleagues asked participants to describe a day in the life of a skinhead. Those who were instructed to avoid the use of stereotypes during this initial writing task chose to sit farther from a skinhead during a subsequent activity-a decision that was taken to indicate a resurgence of negative thoughts (Macrae, Bodenhausen, Milne, \& Jetten, 1994; see also Plant \& Devine, 2001). In Study 3, we examined the possibility that the CB participants' tendency to suppress prejudicial feelings would similarly backfire and ultimately exacerbate negativity toward the Hispanic outgroup.

\section{Study 3}

\section{Method}

Participants and design Fifty White students in an introductory psychology course ( $76 \%$ female) participated in this study in partial completion of a course requirement. ${ }^{5}$ This experiment employed only the high-Conflict condition and assessed prejudice both immediately after the conflict induction and again after a 20-minute delay. The study followed a 3 (Ideology: control vs. $\mathrm{CB}$ vs. MC) $\times 2$ (Time: 1 vs. 2 ) mixed-model design with repeated measures on the latter factor.

Materials and procedure In this study all participants read the high-Conflict article. Otherwise, the procedure (including our manipulation of Ideology and our debriefing) was drawn from Studies 1 and 2.

Measures of pretest bias The psychology department introduced a pretest questionnaire in the semester during which this study was conducted, allowing us to collect thermometer and percent estimate measures several weeks before the experimental session. Except for the response options, which were constrained by the pretest format, these measures were identical to those used in Studies 1 and 2. The thermometer asked participants to rate their feelings toward groups on a scale ranging from 1 (very coolly) to 10 (very warmly). The percent estimate measure asked participants to rate the percentage of Hispanics and Whites who possess each of the eight traits from Study 2 on a scale from $1(0-10 \%)$ to 10 (91-100\%), with each intermediate point labeled accordingly (e.g. $6=51-60 \%)$.

Measures of Time 1 bias After the manipulation of Ideology and the high-Conflict induction, participants were given a long questionnaire entitled Campus Life Survey. The first section of the survey explained that interethnic relations were an important part of campus life and asked participants to rate their feelings toward several groups on a single item, ranging from 1 (very negative) to 7 (very positive). The goal of these items was to assess bias immediately after the Ideology manipulation and the presentation of the high-Conflict scenario. At that point in time, CB participants were presumably frustrated regarding the policy but also felt most strongly the strictures against admitting conflict between ethnic groups. Accordingly, we predicted they would take these measures as an opportunity to 
express egalitarian views, presumably inhibiting any prejudiced reactions (as in Studies 1 and 2). We did not want to overwhelm our participants with questions about prejudice at Time 1 for fear that rehearsing their attitudes would attenuate shifts at Time 2 . This single item therefore provided our only Time 1 measure of bias.

Filler task The remainder of the Campus Life Survey served as a filler task, with questions about participants' familiarity with school resources (e.g. libraries, counseling and resource centers), their academic and social goals for their time in college, etc. The items were drawn from an actual survey conducted by the administration and took approximately 20 minutes to complete.

Measures of Time 2 bias After completing the Campus Life Survey, participants were asked to take a few minutes to fill out a measure that was described as a pilot test for a graduate student's dissertation. Participants were asked to complete percent estimates for a variety of groups, each presented on a different page. Like Study 2, this packet included pages for several groups other than Hispanics and Whites (i.e. gay men, Blacks, and feminists). Unlike Study 2, however, this assessment of bias occurred after a substantial delay during which participants' vigilance regarding the inhibition of prejudice might be expected to wane. For CB participants, who were initially expected to suppress prejudice, this lack of caution was expected to promote a backlash, actually leading to greater expression of intergroup bias.

\section{Results and discussion}

Statistical control Thermometer and percent estimate bias measures, collected during the pretest, were calculated as in Studies 1 and 2, respectively, then standardized and averaged. All analyses in Study 3 were performed with an analysis of covariance (ANCOVA) including this index of pretest bias as a covariate.

Because all participants experienced high Conflict, ratings of helpfulness were not expected to vary by condition. As anticipated, participants generally rated the policy as helpful to minorities (adjusted $M=8.24$ ) and antagonistic to the interests of White students (adjusted $M=2.41$ ). Further, neither rating depended on condition, $F$ values $<1.5, p$ values $>.22$. The pretest covariate was not significantly related to either minority or White helpfulness ratings, $F$ values $(1,44)=1.92,1.89, p$ values $=.17$.

Intergroup bias We examined bias as a function of Ideology and Time. Because the Time 1 and Time 2 measures used different metrics, we first standardized the scores separately at each time point. Though this approach allows us to examine whether the relationships between the three Ideology conditions vary as a function of time, it renders absolute cross-time comparisons effectively meaningless (at both points, the average level of bias is zero because of the standardization). We then submitted them to a $3 \times 2$ mixed-model ANCOVA. This analysis revealed the expected interaction between Time and the $\mathrm{CB}$ versus MC contrast, $F(1$, $44)=16.06, p=.0002$ (see Table 3 ), and between Time and the control versus ideology contrast, $F(1,44)=4.67, p=.036$. We also obtained an unexpected interaction between Time and the pretest covariate, $F(1,44)=4.73, p=.035$. To clarify the meaning of these effects, we analyzed bias separately at Time 1 and Time 2 .

Time 1 bias Tests of bias at Time 1 replicated the high-Conflict conditions in Studies 1 and 2, such that participants in the $\mathrm{CB}$ condition reported less bias than participants in the MC condition,

Table 3. Adjusted means of standardized intergroup bias as a function of Ideology (control, colorblind or multicultural) and Time from Study 3

\begin{tabular}{llrr}
\hline & \multicolumn{3}{c}{ Ideology } \\
\cline { 2 - 4 } & Control & \multicolumn{1}{c}{ CB } & MC \\
\hline Time 1 & 0.40 & -0.38 & 0.08 \\
Time 2 & 0.03 & 0.15 & -0.18 \\
\hline
\end{tabular}

Note: Time 1 bias is based on warmth-type Likert ratings of Whites minus Hispanics. Time 2 bias reflects percent estimate ratings of the prevalence of positive minus negative traits among Whites minus Hispanics. Each bias measure was standardized prior to analysis. 
$F(1,45)=3.57, p=.056$. The contrast pitting control participants against the average of the two ideological conditions was not significant, $F(1,45)=1.44, p=.24$, though-as is clear from the adjusted means-controls expressed relatively high levels of bias. The pretest bias covariate was significant, $F(1,45)=7.72, p=.008$, and positively related to Time 1 bias, presumably reflecting stable individual differences in attitudes toward Hispanics and Whites.

Time 2 bias A very different pattern emerged at Time 2. After the 20-minute delay, and in an ostensibly different context, participants in the $\mathrm{CB}$ condition reported higher levels of bias than participants in the MC condition, $F(1$, $44)=8.29, p=.006$. Again, the control condition did not differ from the average of $\mathrm{CB}$ and $\mathrm{MC}, F(1,44)=1.79, p=.19$, and the pretest bias covariate was significant, $F(1,44)=24.64$, $p<.0001$. Moreover-as indicated by the significant interaction between Time and the pretest covariate-this effect was stronger at Time 2 than Time 1. This probably reflects the fact that the pretest measures were more similar in structure to the dependent variables at Time 2 than at Time 1.

To specifically test the possibility of a rebound, we also calculated the difference between Time 2 bias and baseline (pretest) bias, with positive scores reflecting an increase in bias at Time 2. CB participants showed a significant increase, suggesting a rebound to levels above baseline, $F(1,45)=5.57, p=.023$. MC participants actually showed a significant decrease relative to baseline, $F(1,45)=4.08, p=.049 .{ }^{6}$

Initially, in a high-conflict situation, CB participants expressed less intergroup bias than MC participants, but these same participants subsequently rebounded, showing higher levels of bias than their MC counterparts. We suggest that this boomerang pattern stems from the CB participants' attempts to suppress feelings of negativity that stem from the intergroup conflict (as in Study 2) because-from a CB perspective-these feelings threaten intergroup harmony. Ironically, this early suppression seems to exacerbate prejudice in the long run. The MC participants, for whom group differences may be more acceptable, showed no such rebound.

One may reasonably wonder if the results of Studies 1-3 reflect differences between MC and CB strategies, broadly speaking, or if instead they depend on some particular aspect of our manipulation. Perhaps, for example, a participant who adopts a $\mathrm{CB}$ perspective because she is, in essence, asked to do so does not adhere to this ideology in quite the same way as a participant who naturally adopts a CB mindset for personal reasons. In Study 4, we therefore sought to replicate Study 3's basic finding, but in this final study we measured ideology rather than manipulating it.

\section{Study 4}

In Study 4, prior to the experimental session, participants rated their endorsement of both $\mathrm{CB}$ and MC ideologies during mass pretesting. In the lab, we then manipulated conflict and, after a 20-minute delay, assessed intergroup bias. Study 4 therefore focuses on the post-delay consequences of conflict for both $\mathrm{CB}$ and MC ideologies. The results of Studies 1-3 suggest that, when conflict is low, both $\mathrm{CB}$ and $\mathrm{MC}$ ideologies can reduce bias. Although we have not yet tested the longevity of that effect, we have no a priori reason to predict that it will change as a function of a delay. That is, in the low-Conflict condition, we have no reason to believe that either CB or MC participants are suppressing resentment (after all, there is no conflict), and so, we have no reason to predict that bias will rebound for either ideology. When Conflict is high, by contrast, CB participants in Study 3 showed evidence of rebound effects, reporting greater bias than MC participants after a 20-minute delay. Based on these results, we can derive predictions for Study 4. Since both strategies effectively reduce bias when Conflict is low, we expect that stronger endorsement of either ideology should be associated with lower levels of bias. That is, in the absence of conflict, it should make little difference whether participants prefer a CB or MC point of view. Support for either perspective should yield 
relatively favorable ratings of the outgroup. When conflict increases, however, preference for a particular ideology over the other should begin to matter more. In other words, we expect the level of Conflict to interact with participants' ideological preferences. In essence, as the level of Conflict increases, multiculturalism should become a more effective strategy, with MC participants reporting less post-delay bias than those preferring a $\mathrm{CB}$ view.

\section{Method}

Participants Seventy White students $(50 \%$ female) in an introductory psychology course at the University of Colorado (CU) took part in this study, in partial completion of a course requirement. ${ }^{7}$

Design Unlike Studies 1-3, Study 4 involved no manipulation of ideology. Instead, during a mass pretesting, participants were asked to complete a questionnaire assessing personal endorsement of $\mathrm{CB}$ and MC ideologies. During the experimental session, we assigned participants to one of two levels of Conflict, low versus high. The design of the study, then, involved a simple between-participant manipulation of Conflict (low vs. high) with both CB and MC ideologies measured continuously as individual-difference variables.

\section{Materials and procedure}

Ideology measurement Two five-item ideology measures were taken from Wolsko (2002; Wolsko et al., 2006). Participants were asked to respond to questions such as 'To create a harmonious society, we must look beyond skin color and understand the person within, to see each person as an individual who is part of the larger group, "Americans"” $(\mathrm{CB}$, alpha $=.81)$, or "Understanding both the similarities and differences among ethnic groups is an essential component of long-term social harmony in the United States' $(\mathrm{MC}$, alpha $=.86)$. Responses were made on a 7-point Likert scale ranging from 1 (strongly disagree) to 7 (strongly agree).

Conflict manipulation (newspaper article) Manipulation of Conflict was accomplished as in Studies 1 and 2. Again, participants completed a manipulation check, rating the degree to which the proposed policy would increase or decrease minority and White students' chances of registering for classes.

Delay Participants next completed a series of filler tasks, which took approximately 20 minutes.

Measures of intergroup bias After the delay, participants completed measures of intergroup bias. This packet included a thermometer as well as semantic differential scales. Participants were asked to rate Hispanics and Whites (embedded in a variety of other groups) on 11 seven-point scales anchored by positive and negative adjective adjectives with no stereotype content (e.g. nice-awful, cruel-kind). Finally, participants were extensively debriefed.

\section{Results and discussion}

Manipulation checks As in Studies 1 and 2, we assessed the effect of our Conflict manipulation by examining participants' reports concerning the effect of the registration policy. Again, participants in both conditions felt that the policy would help minorities, and that perception did not depend on conflict (high Conflict $M=8.10$, low Conflict $M=8.00), F(1,68)=0.22, p=64$. However, participants in the high-Conflict condition $(M=2.66)$ rated the policy as much more costly to Whites than did the low-Conflict participants $(M=4.12), F(1,68)=16.97$, $p<.0001$. Again, these data suggest that our conflict manipulation was successful: in the highConflict condition, the outgroup's gain comes at a cost to the ingroup.

Intergroup bias We computed two indices of bias, one based on the thermometer, and one based on the semantic differential. Thermometer bias was calculated as before. For the semantic differentials, we calculated the degree to which participants rated Whites and (separately) Hispanics more positively than negatively, then calculated the difference between ratings of the two target groups. For both thermometer and semantic differential indices, higher scores 
reflect greater positivity toward Whites than toward Hispanics. The two measures were correlated, $r(68)=.65, p<.0001$, and to improve reliability, we standardized and averaged them to form an overall bias index.

Our primary predictions for Study 4 were that endorsement of either the $\mathrm{CB}$ or MC ideology would reduce bias in the low-Conflict condition, but that Conflict would interact with ideological preference, such that as Conflict increased, multiculturalism would become a more effective prejudice-reduction strategy than colorblindness. Assessing these effects in a measurement study is complicated by the fact that $\mathrm{CB}$ and MC ideologies are not necessarily mutually exclusive. Indeed, many participants endorsed elements of both ideologies, and the two measures were significantly correlated, $r(68)=0.48, p<.0001$. In essence, this overlap between the scales may represent general support for ethnic or racial equality, regardless of the manner $(\mathrm{CB}$ or $\mathrm{MC})$ in which that equality is obtained.

To address this overlap statistically, we computed two indices. The first index is the computed average of the $\mathrm{CB}$ and MC measures. Conceptually, it represents a general desire for intergroup harmony regardless of ideology. The second index is the difference between the measures $(\mathrm{CB}-\mathrm{MC})$, and represents the preference for a $\mathrm{CB}$, rather than an MC, approach to intergroup relations. It is important to note that these two indices correspond nicely to our dual predictions for this study. First, endorsement of either ideology (or both) is reflected in the average, and this average should be associated with a reduction in bias when conflict is low. Second, a preference for colorblindness versus multiculturalism is reflected in the difference score, which should interact with the level of Conflict, such that-as conflict increases-multiculturalism reduces prejudice more effectively than colorblindness. To test these hypotheses, we regressed our index of intergroup bias on the $\mathrm{CB}-\mathrm{MC}$ average, the CB-MC difference (both mean centered), a contrast code reflecting our Conflict condition and the interactions of Conflict with both the average and the difference scores.
This analysis revealed several interesting effects. As in Studies 1 and 2, we found that an increase in the level of Conflict led to a counterintuitive decrease in reported bias, $F(1,64)=5.06$, $p<.028$. More germane to our first prediction, Conflict interacted with the $\mathrm{CB}-\mathrm{MC}$ average, $F(1,64)=3.88, p<.053$. To elucidate this effect, we analyzed the effects of the CB-MC average once in the low-Conflict condition and once in the high-Conflict condition. In line with our predictions, when Conflict was low, participants with higher scores on both CB and MC scales (a higher average, or greater preference for group equality regardless of strategy) reported less prejudice than those with lower average scores, $F(1,64)=5.57, p<.021$. When Conflict was high, this relationship weakened to the point that the $\mathrm{CB}-\mathrm{MC}$ average was completely unrelated to reported bias, $F(1,64)=0.12, p<.72$.

We also observed the predicted interaction between Conflict and the CB-MC difference score, $F(1,64)=3.67, p<.059$. Strategy preference (CB vs. MC) made no difference on average, $F(1,64)=0.48, p<.49$. But, in line with predictions, as the level of Conflict increased, endorsement of a multicultural perspective was associated with lower levels of bias than endorsement of a colorblind perspective.

As final perspectives on these data, we analyzed the bias index twice more. Once as a function of MC endorsement, Conflict, and the $\mathrm{MC} \times$ Conflict interaction; and once as a function of $\mathrm{CB}$ endorsement, Conflict, and the $\mathrm{CB} \times$ Conflict interaction. The MC analysis revealed a marginal main effect such that stronger endorsement of multiculturalism tended to reduce bias on average, $F(1,66)=2.69$, $p=.10$. Importantly, and as predicted, this pattern was not moderated by the level of Conflict, $F(1,66)=1.14, p<.29$.

Turning to the CB analysis, we observed a very different pattern of results. On average, stronger endorsement of a CB perspective was not significantly associated with a reduction in bias, $F(1,66)=2.28, p<.14$. However, the effect of $\mathrm{CB}$ endorsement depended heavily on the level of Conflict, as attested by the $\mathrm{CB} \times$ Conflict interaction, $F(1,66)=8.76, p<.005$. When Conflict was low, participants who endorsed 
colorblindness showed clear reductions in bias, $F(1,66)=8.35, p<.005$. But when Conflict was high, this beneficial effect of CB ideology disappeared and even reversed direction, though not significantly so, $F(1,66)=1.30, p<.26$.

The data from Study 4, in which bias was assessed after a delay, conform fairly well to our predictions and our prior results. In line with Studies 1 and 2, support for both ideologies tends to reduce intergroup bias when conflict is low. But this generalized benefit weakens under high-Conflict conditions. At the same time (and in line with Study 3), the induction of Conflict tends to increase the post-delay efficacy of an $\mathrm{MC}$ perspective (relative to a $\mathrm{CB}$ perspective). Further, Conflict does not seem to moderate the efficacy of a MC approach to prejudice reduction, but it has dramatic effects on the efficacy of colorblindness. In sum, then, this correlational study largely replicates the results of Study 3's experimental manipulation.

\section{General discussion}

In four studies, we tested the efficacy of $\mathrm{CB}$ and MC bias-reduction strategies in situations characterized by either low or high levels of ethnic conflict. In Studies 1 and 2, when Conflict was low, White participants who were induced to accept $\mathrm{CB}$ and MC ideologies exhibited less prejudice than controls. These effects replicate previous work showing that the two strategies reduce bias in roughly equal measure (Wolsko et al., 2000). In the highConflict conditions, however, a different pattern emerged: CB participants reported lower levels of prejudice than MC participants. Indeed, for $\mathrm{CB}$ participants, manipulations that increased the severity of conflict tended to counterintuitively reduce the expression of bias. This pattern violates the assumption that greater conflict promotes greater hostility (Sherif et al., 1961) and raises the possibility that CB participants inhibited any resentment they may have felt due to the conflict. We reasoned that, for CB participants, a dispute between groups threatens the principle tenet of their ideology. The emotion-laden conflict of interest, in essence, threatens to prove that group differences do matter-that the participants cannot ignore ethnicity. To address this threat, CB participants may suppress their initial frustration. Study 2 examined suppression, using an implicit measure of bias designed to impair strategic control. In Study 2, CB participants in the high-Conflict situation reported less bias on explicit measures (relative to MC participants), but as predicted they exhibited greater bias on the implicit measure. In Study 3, we examined the possibility that the CB participants' self-restraint would reduce the expression of prejudice in the short term but that, once their vigilance faltered, prejudice would rebound (an ironic-process effect; Wegner et al., 1987). As predicted, results from this study showed that, although bias in a high-Conflict situation initially dropped, CB participants reported greater prejudice when re-assessed after a 20-minute delay. Finally, Study 4 provided a conceptual replication of Study 3, showing that the longterm effects of $\mathrm{CB}$ and $\mathrm{MC}$ strategies hold even when ideology is measured rather than manipulated. After a 20-minute delay, participants who endorsed an MC perspective showed marginal reductions in bias, and this effect was not moderated by Conflict. Participants who endorsed a $\mathrm{CB}$ view showed reductions in bias when Conflict was low, but the benefits of this perspective vanished when Conflict was high.

A CB ideology is predicated on the idea that groups are fundamentally the same. These studies suggest that participants who adopted such an ideology experienced a struggle in situations characterized by intergroup conflict. Though they did not express prejudice openly, conflict-induced bias manifested itself on more subtle implicit measures and in situations that were temporally removed from the Conflict induction. Participants who adopted an MC ideology, which allows and even encourages the recognition of group differences, initially expressed greater bias in high-conflict situations. Perhaps as a consequence, these individuals showed no dissociation between implicit and explicit measures, nor did they exhibit ironicprocess effects.

It may be argued that the registration policy used to manipulate conflict in the present 
studies is, by its nature, more consistent with multiculturalism than with colorblindness. After all, the policy would have given preferential treatment to minorities, thus recognizing (rather than minimizing) group differences. Is it surprising, then, that CB participants responded with some negativity? This seems an interesting question, and future research might profitably manipulate the nature of such a policy (e.g. inducing conflict by implementing a CB policy that eliminates privileges, such as affirmative action, traditionally afforded to one group). However, for a variety of reasons, we do not believe that the results of these studies reflect the MC nature of the registration policy. First, and most obviously, the MC aspect of the policy was held constant. In both the high- and low-Conflict conditions, minority students stood to gain special access to classes. The difference between the conditions was simply the degree to which White students would suffer as a result. In other words, we manipulated the degree to which the policy created a zero-sum situation, not the degree to which the policy recognized group differences. Accordingly, effects of our independent variable, Conflict, cannot be attributed to changes in the MC nature of the policy. Second, the results clearly indicate that participants in the MC condition were as resistant to the high-Conflict policy as anybody else. In no case did the MC condition rate the policy as less damaging to the interests of White students than did the other conditions. Third, on initial measures of bias-implicit as well as explicit-MC participants expressed levels of prejudice as great as or greater than those expressed by CB participants (Studies 1 and 2, Study 3 Time 1). It certainly does not seem then that MC participants responded more favorably to the policy.

The behavior of the control participants in these studies warrants discussion. As noted earlier, controls expressed greater prejudice than either CB or MC participants when conflict was absent (Studies 1 and 2). When conflict was high, however, controls showed a less consistent pattern of effects. In Study 1, they seemed to mirror the CB participants (exhibiting lower levels of bias than MC participants); in Studies
2 and 3 , however, controls looked more similar to the MC condition (exhibiting higher levels of bias at early stages, and lower bias after the delay in Study 3 relative to CB participants). Although we have no definitive information about the cause of this shift, it is possible that participants in the control condition (who were simply asked to spend time thinking about ethnic relations) generated qualitatively different kinds of thoughts across the three studies, sometimes leaning more toward a CB ideology, and other times leaning more toward multiculturalism. Certainly, Study 4 suggests that naturally occurring individual differences in ideology can produce effects that generally mirror our experimental manipulations. In combination with the tension of the highConflict condition, these spontaneous thoughts may have evoked very different reactions. Such fluctuations obviously complicate our attempts to understand the effects of conflict, but we feel that our conclusions regarding the $\mathrm{CB}$ condition's resistance and rebound remain largely unchanged.

The findings of the present studies seem congruent with the suggestion, advanced by Pettigrew (2000) and Gaertner and Dovidio (Gaertner et al., 2000), that efforts to improve intergroup relations might profit from the use of multiple prejudice-reduction strategies. By tailoring the strategy to the situation, groups may progress toward greater levels of harmony. During periods of greater hostility, CB strategies may serve a valuable purpose. For example, by characterizing group members simply as individuals-fundamentally the same and fundamentally equal-decategorization may erode group divisions and begin to open channels of communication. Similarly, recategorization the recognition of a common, superordinate identity) may inspire thoughts of common fate and positive interdependence between the groups. Even if these strategies induce a degree of tension among group members, the present studies suggest that the $\mathrm{CB}$ approach can reduce the immediate, explicit expression of prejudice. By doing so, these strategies may pave the way for improved relations. In a similar vein, Nicole Shelton and her colleagues (Shelton, Richeson, 
Salvatore, \& Trawalter, 2005) suggest that highprejudice Whites may engage in greater selfregulation when interacting with a Black partner, and this effort may promote a more positive interaction. Somewhat ironically, Black participants in their study reported greater liking for high-prejudiced (rather than low-prejudiced) White interaction partners. These findings make sense to the extent that privately held prejudice led these individuals to display an especially positive public façade, much like the colorblind participants in Study 2. This discretion may serve a valuable function by facilitating initial positive intergroup interaction. At the same time, that façade may eventually break down under the wear and tear of long-term interaction. The ultimate success of a relationship may have more to do with deep-seated biases and depend less on the individual's motivation (Towles-Schwen \& Fazio, 2006). Once members of the two groups have established a tentative working relationship, therefore, MC strategies may further reduce prejudice and allow individuals to recognize and appreciate the unique strengths of their own group as well as those of the outgroup. If those differences subsequently give rise to the occasional dispute, multiculturalism may also help group members see the conflict in a broader, more positive intergroup context.

In an increasingly diverse society, contact and conflict between groups is inevitable. Moreover, these encounters may often have serious, psychologically meaningful consequences for the people involved. Jobs may be lost, property values may drop, cherished beliefs and customs may collide. To fully understand the utility of interventions intended to improve intergroup relations, experimental research must examine their efficacy in situations that involve participants personally and emotionally. Creating this tension (ethically) in the laboratory is not a trivial task, but—as these studies show-doing so may yield results that differ dramatically from results obtained in more typical experimental settings.

\section{Notes}

1. We excluded four White participants from the analyses. Three questioned the veracity of the manipulation (one each in the $\mathrm{CB} /$ high-Conflict, $\mathrm{CB} /$ low-Conflict, and $\mathrm{MC}$ /low-Conflict conditions), and one (CB/high) was an outlier in the analysis with a Cook's $D$ of .098 .

2. Degrees of freedom are reduced for some analyses in each study due to missing data (Study 1: distinctiveness; Study 2: helpfulness; Study 3: Time 2 bias).

3. We excluded five participants. Two had incomplete data on the EAST due to experimenter error; one control/low-Conflict participant questioned the article; one control/ high-Conflict participant expressed openly racist attitudes on an initial questionnaire (prior to the manipulation); and one MC/low-Conflict participant was an outlier on the EAST with a Cook's $D$ of .088 .

4. Explicit Bias $=\beta_{0}+\beta_{1} *$ Conflict $+\beta_{2} *$ Ideol versus Control $+\beta_{3} * \mathrm{CB}$ versus $\mathrm{MC}+\beta_{4} *$ Implicit Bias $+\beta_{5} *$ (Ideol vs. Control * Implicit Bias $)+\beta_{6} *$ (CB vs. MC * Implicit Bias $)$.

5. We excluded one CB participant who was an outlier on the Time 2 prejudice measure with Cook's $D$ of .17 .

6. Analyses controlling for pretest scores (rather than calculating a difference score) yield similar results.

7. We excluded three outliers (Cook's $D>.11$ ) from the analyses. If these individuals are included, the critical interaction between Conflict and the MC-CB difference score actually becomes stronger, $F(1,67)=6.55, p<.01$.

\section{Acknowledgments}

This material is based upon work supported under a NSF Graduate Research Fellowship and NIMH grant F31-MH069017 to the first author. Support also came from NIMH grant R01-45049 to the second author. We wish to thank the members of the C.U. Stereotyping and Prejudice laboratory for their comments, and Dr Brandy Reed for her care in conducting this research.

\section{References}

Brewer, M. B. (1988). A dual-process model of impression formation. Advances in Social Cognition, 1, 1-36.

Brewer, M. B. (1991). The social self: On being the same and different at the same time. Personality and Social Psychology Bulletin, 17, 475-482. 
Brewer, M. B., \& Brown, R. (1998). Intergroup relations. In D. T. Gilbert, S. T. Fiske, \& G. Lindsey (Eds.), Handbook of social psychology (pp. 554-594). Boston: McGraw Hill.

Brewer, M. B., \& Miller, N. (1984). Beyond the contact hypothesis: Theoretical perspectives on desegregation. In N. Miller \& M. Brewer (Eds.), Groups in contact: The psychology of desegregation (pp. 281-302). Orlando, FL: Academic Press.

Brown, R., \& Wade, G. (1987). Superordinate goals and intergroup behaviour: The effect of role ambiguity and status on intergroup attitudes and task performance. European Journal of Social Psychology, 17, 131-142.

Campbell, D. T. (1967). Stereotypes and the perception of group differences. American Psychologist, 22, 817-829.

Correll, J., \& Park, B. (2005). A model of the ingroup as a social resource. Personality $\mathcal{E}$ Social Psychology Review, 9, 341-359.

Crocker, J., \& Major, B. (1989). Social stigma and self-esteem: The self-protective properties of stigma. Psychological Review, 96, 608-630.

Day, J. C. (1996). Population projections of the United States by age, sex, race, and Hispanic Origin: 1995 to 2050. U.S. Bureau of the Census, Current Population Reports, P251130. Washington, DC: U.S. Government Printing Office.

De Houwer, J. (2003). The extrinsic affective Simon task. Experimental Psychology, 50, 77-85.

Deffenbacher, D. M., Park, B., Judd, C. M., \& Correll, J. (2007). Does the accentuation of category boundaries necessarily increase intergroup bias? Manuscript in preparation.

Devine, P. G. (1989). Stereotypes and prejudice: Their automatic and controlled components. Journal of Personality and Social Psychology, 56, 5-18.

Esses, V. M., Jackson, L. M., \& Armstrong, T. L. (1998). Intergroup competition and attitudes toward immigrants and immigration: An instrumental model of group conflict. Journal of Social Issues, 54, 699-724.

Fazio, R. H., Jackson, J. R., Dunton, B. C., \& Williams, C. J. (1995). Variability in automatic activation as an unobtrusive measure of racial attitudes: A bona fide pipeline? Journal of Personality and Social Psychology, 69, 1013-1027.

Gaertner, S. L., Dovidio, J. F., Banker, B. S., Houlette, M., Johnson, K., \& McGlynn, E. (2000). Reducing intergroup conflict: From superordinate goals to decategorization, recategorization and mutual differentiation. Group Dynamics, 4, 98-114.
Gaertner, S. L., Dovidio, J. F., Nier, J. A., Ward, C. M., \& Banker, B. S. (1999). Across cultural divides: The value of a superordinate identity. In D. A. Prentice \& D. T. Miller (Eds.), Cultural divides: Understanding and overcoming group conflict (pp. 173-212). New York: Russell Sage.

Gaertner, S. L., Mann, J., Murrell, A., \& Dovidio, J. F. (1989). Reducing intergroup bias: The benefits of recategorization. Journal of Personality and Social Psychology, 57, 239-249.

Greenwald, A. G., McGhee, D. E., \& Schwartz, J. L. K. (1998). Measuring individual differences in implicit cognition: The implicit association test. Journal of Personality and Social Psychology, 74, 1464-1480.

Hewstone, M., \& Brown, R. (1986). Contact is not enough: An intergroup perspective on the 'contact hypothesis'. In M. Hewstone \& R. Brown (Eds.), Contact and conflict in intergroup encounters (pp. 1-44). Oxford: Blackwell.

Hewstone, M., Rubin, M., \& Willis, H. (2002). Intergroup bias. Annual Review of Psychology, 53, 575-604.

Hornsey, M. J., \& Hogg, M. A. (2000). Assimilation and diversity: An integrative model of subgroup relations. Personality E Social Psychology Review, 4, $143-156$.

Ito, T. A., \& Urland, G. R. (2003). Race and gender on the brain: Electrocortical measures of attention to the race and gender of multiply categorizable individuals. Journal of Personality and Social Psychology, 85, 616-626.

Macrae, C. N., Bodenhausen, G. V., Milne, A. B., \& Jetten, J. (1994). Out of mind but back in sight: Stereotypes on the rebound. Journal of Personality and Social Psychology, 67, 808-817.

Miller, D. T., \& Prentice, D. A. (1999). Some consequences of a belief in group essence: The category divide hypothesis. In D. A. Prentice \& D. T. Miller (Eds.), Cultural divides: Understanding and overcoming group conflict (pp. 213-238). New York: Russell Sage Foundation.

Mummendey, A., \& Wenzel, M. (1999). Social discrimination and tolerance in intergroup relations: Reactions to intergroup difference. Personality and Social Psychology Review, 3, 158-174.

Levine, R. A., \& Campbell, D. T. (1972). Ethnocentrism: Theories of conflict, ethnic attitudes and group behavior. New York: Wiley.

Park, B., \& Judd, C. M. (2005). Rethinking the link between categorization and prejudice within the social cognition perspective. Personality and Social Psychology Review, 9, 108-130. 
Peabody, D. (1967). Trait inferences: Evaluative and descriptive aspects. Journal of Personality and Social Psychology, 7, 1-18.

Pettigrew, T. F. (2000). Reducing intergroup conflict with optimal intergroup contact. International Journal of Psychology, 35, 193.

Pickett, C. L., \& Brewer, M. B. (2001). Assimilation and differentiation needs as motivational determinants of perceived in-group and out-group homogeneity. Journal of Experimental Social Psychology, 37, 341-348.

Plant, E. A., \& Devine, P. G. (1998). Internal and external motivation to respond without prejudice. Journal of Personality $\mathcal{E}$ Social Psychology, 75, 811-832.

Plant, E. A., \& Devine, P. G. (2001). Responses to other-imposed pro-Black pressure: Acceptance or backlash? Journal of Experimental Social Psychology, 37, 486-501.

Richeson, J. A., \& Nussbaum, R. J. (2004). The impact of multiculturalism versus color-blindness on racial bias. Journal of Experimental Social Psychology, 40, 417-423.

Shelton, J. N., Richeson, J. A., Salvatore, J., \& Trawalter, S. (2005). Ironic effects of racial bias during interracial interactions. Psychological Science, 16, 397-402.

Sherif, M., Harvey, O. J., White, B. J., Hood, W. R., \& Sherif, C. (1961). Intergroup conflict and cooperation: The Robbers' Cave experiment. Norman, OK: Oklahoma Book Exchange.

Sidanius, J., \& Pratto, F. (1999). Social dominance: An intergroup theory of social hierarchy and oppression. New York: Cambridge University Press.

Stroop, J. R. (1935). Studies of interference in serial verbal reactions. Journal of Experimental Psychology, 18, 643-662.

Towles-Schwen, T., \& Fazio, R. H. (2006). Automatically activated racial attitudes as predictors of the success of interracial roommate relationships. Journal of Experimental Social Psychology, 42, 698-705.
Wegner, D. M., Schneider, D. J., Carter, S., \& White, T. (1987). Paradoxical effects of thought suppression. Journal of Personality and Social Psychology, 53, 5-13.

Wolsko, C. V. (2002). The measurement and consequences of interethnic ideology. (Doctoral dissertation, University of Colorado, February 2002) Dissertation Abstracts International, 62, 3853.

Wolsko, C., Park, B., \& Judd, C.M. (2006). Considering the Tower of Babel: Correlates of assimilation and multiculturalism among ethnic minority and majority groups in the United States. Social Justice Research, 19, 277-306.

Wolsko, C., Park, B., Judd, C. M., \& Wittenbrink, B. (2000). Framing interethnic ideology: Effects of multicultural and color-blind perspectives on judgments of groups and individuals. Journal of Personality \& Social Psychology, 78, 635-654.

Paper received 3 May 2006; revised version accepted 1 March 2008.

\section{Biographical notes}

JOSHUA CORRELL is an assistant professor of psychology at the University of Chicago. His research focuses on stereotyping and prejudice, with a particular focus on the stereotypes related to threat or danger.

BERNADETTE PARK is a professor of psychology at the University of Colorado at Boulder. Her research interests include the study of stereotyping, prejudice, and intergroup relations, and various methodological techniques for examining these issues.

J. ALLEGRA SMITH is a graduate student of social psychology at the University of Colorado at Boulder. Her research focuses on social problems such as stereotyping and prejudice, along with interventions designed to alleviate the negative impacts of these phenomena. 